\title{
GT2017-65128
}

\section{A DYNAMIC MODEL FOR THE EVALUATION OF AIRCRAFT ENGINE ICING DETECTION AND CONTROL-BASED MITIGATION STRATEGIES}

\author{
Donald L. Simon \\ NASA Glenn Research Center \\ 21000 Brookpark Road \\ Cleveland, $\mathrm{OH}, 44135$
}

\author{
Aidan W. Rinehart \\ Vantage Partners, LLC \\ 3000 Aerospace Parkway \\ Brook Park, OH 44142
}

\author{
Scott M. Jones \\ NASA Glenn Research Center \\ 21000 Brookpark \\ Cleveland, $\mathrm{OH} 44135$
}

\section{ABSTRACT}

Aircraft flying in regions of high ice crystal concentrations are susceptible to the buildup of ice within the compression system of their gas turbine engines. This ice buildup can restrict engine airflow and cause an uncommanded loss of thrust, also known as engine rollback, which poses a potential safety hazard. The aviation community is conducting research to understand this phenomena, and to identify avoidance and mitigation strategies to address the concern. To support this research, a dynamic turbofan engine model has been created to enable the development and evaluation of engine icing detection and control-based mitigation strategies. This model captures the dynamic engine response due to high ice water ingestion and the buildup of ice blockage in the engine's low pressure compressor. It includes a fuel control system allowing engine closed-loop control effects during engine icing events to be emulated. The model also includes bleed air valve and horsepower extraction actuators that, when modulated, change overall engine operating performance. This system-level model has been developed and compared against test data acquired from an aircraft turbofan engine undergoing engine icing studies in an altitude test facility and also against outputs from the manufacturer's customer deck. This paper will describe the model and show results of its dynamic response under openloop and closed-loop control operating scenarios in the presence of ice blockage buildup compared against engine test cell data. Planned follow-on use of the model for the development and evaluation of icing detection and controlbased mitigation strategies will also be discussed. The intent is to combine the model and control mitigation logic with an engine icing risk calculation tool capable of predicting the risk of engine icing based on current operating conditions. Upon detection of an operating region of risk for engine icing events, the control mitigation logic will seek to change the engine's operating point to a region of lower risk through the modulation of available control actuators while maintaining the desired engine thrust output. Follow-on work will assess the feasibility and effectiveness of such control-based mitigation strategies.

\section{INTRODUCTION}

Airborne ice crystals can pose an operational hazard to aircraft gas turbine engines. Since 1990, there have been over 100 reported cases of engine power loss due to ice accretion within the engine's compression system $[1,2,3]$. When flying in high ice water content conditions, frozen ice crystals can be ingested by the engine and then impinge on warm engine surfaces, causing the particles to partially melt and begin to accrete. This can lead to the buildup of ice within the core of the engine, blocking airflow and resulting in an uncommanded loss of thrust, also known as an engine rollback event.

Within the aviation community, much work is ongoing to characterize the environmental conditions under which engine icing can occur $[4,5,6,7,8,9,10]$ and understand the mechanisms by which ice particles can accrete on compressor components $[11,12,13,14,15]$. Example collaborative efforts include the Engine Icing Working Group (EIWG), a joint committee of international government and industry representatives coordinating research in the area of engine ice crystal icing, and the Ice Crystal Consortium (ICC), a group of engine and airframe manufacturers formed to combine resources to address the problem. Notable engine testing has also recently been conducted at the NASA Glenn Research Center (GRC) Propulsion System Laboratory (PSL) [16], an altitude test facility that has been modified to enable engine testing in simulated high ice water content conditions [17]. Flight test campaigns have also been conducted to understand ice crystal icing conditions and to assess the ability of radar and meteorological probes to detect such conditions $[18,19,20,21,22]$. The experimental results acquired from engine testing and flight testing have been key in advancing the understanding of the engine icing phenomena. 
Avoidance of flight through high ice crystal concentration atmospheric conditions and re-design of compressor hardware to make engines less susceptible to icing are potential solutions, and much of the current research is focused on these areas. However, additional benefit can be gained by taking a systems level approach to understand how engine system-level performance changes when exposed to icing conditions and evaluating what mitigation steps can be taken to reduce the risk of engine icing. Towards this objective, this paper will present a dynamic aircraft engine model created to facilitate the development and evaluation of aircraft engine icing detection and control-based icing risk mitigation strategies. The remaining sections of this paper will present the vision for a control-based mitigation approach. Next, a description of the model will be provided. This will be followed by a comparison of the model against engine test data acquired from NASA GRC PSL testing and outputs from the manufacturer's customer deck. The paper will conclude with a discussion of the next steps and a summary.

\section{NOMENCLATURE}

$\begin{array}{ll}c_{\text {ice }} & \text { Specific heat of ice } \\ c_{\text {steam }} & \text { Specific heat of water vapor } \\ c_{\text {water }} & \text { Specific heat of water } \\ \text { COMDES } & \text { Mean-line compressor design code } \\ \text { dTamb } & \text { Delta between actual and standard temperature } \\ \text { EIWG } & \text { Engine Icing Working Group } \\ \text { GRC } & \text { Glenn Research Center } \\ H_{f} & \text { Heat of fusion for ice } \\ H_{v} & \text { Heat of vaporization for water } \\ \text { HPC } & \text { High Pressure Compressor } \\ \text { HPT } & \text { High Pressure Turbine } \\ \text { ICC } & \text { Ice Crystal Consortium } \\ \text { ISA } & \text { International Standard Atmosphere } \\ \text { LPC } & \text { Low Pressure Compressor } \\ \text { LPT } & \text { Low Pressure Turbine } \\ \text { MVD } & \text { Median Volumetric Diameter } \\ \text { N1 } & \text { Fan speed } \\ \text { N2 } & \text { Core speed } \\ \text { NPSS } & \text { Numerical Propulsion System Simulation } \\ \text { P25 } & \text { Low pressure compressor exit pressure } \\ \text { P3 } & \text { High pressure compressor exit pressure } \\ \text { PLA } & \text { Power Lever Angle } \\ \text { PSL } & \text { Propulsion System Laboratory } \\ Q_{L P C} & \text { Heat loss rate in the low pressure compressor } \\ Q_{H P C} & \text { Heat loss rate in the high pressure compressor } \\ \text { T2 } & \text { Fan hub and LPC inlet temperature } \\ \text { T25 } & \text { Low pressure compressor exit temperature } \\ \text { T3 } & \text { High pressure compressor exit temperature } \\ \text { T45 } & \text { Exhaust gas temperature } \\ \text { T-MATS } & \text { Toolbox for the Modeling and Analysis of } \\ \text { W2 } & \text { Thermodynamic Systems } \\ \text { W25 } & \text { Fan hub and LPC inlet air flow } \\ \text { W3 } & \text { High pressure compressor exit air flow } \\ \text { Wf } & \text { Fuel flow } \\ & \end{array}$

\section{CONTROL-BASED ICING RISK MITIGATION}

Figure 1 shows the envisioned control-based icing risk mitigation architecture. The objective of this architecture is to provide early onset detection of engine icing initiation or icing risk, and then, through the modulation of available control actuators, adjust the engine's operating point to a condition of lower ice accretion risk. Integral to this architecture is icing risk assessment logic. Researchers at NASA GRC have developed a computational tool to estimate the risk of ice accretion and its effect on turbofan engine performance [23]. This tool includes an engine system thermodynamic cycle code, coupled with a compressor flow analysis code, and an ice particle code that has the capability of determining the rate of sublimation, melting, and evaporation of ice particles as they pass through the compressor. This tool, or a modified version of it suitable for real-time implementation, will be included in the active control icing risk mitigation architecture shown in Figure 1. A simplistic solution is desired in implementing this architecture, striving to use available sensors and actuators if possible, and arriving at a computationally efficient implementation. Solutions that minimize impact on engine operating performance are also required, where the requested thrust output of the engine is not compromised.

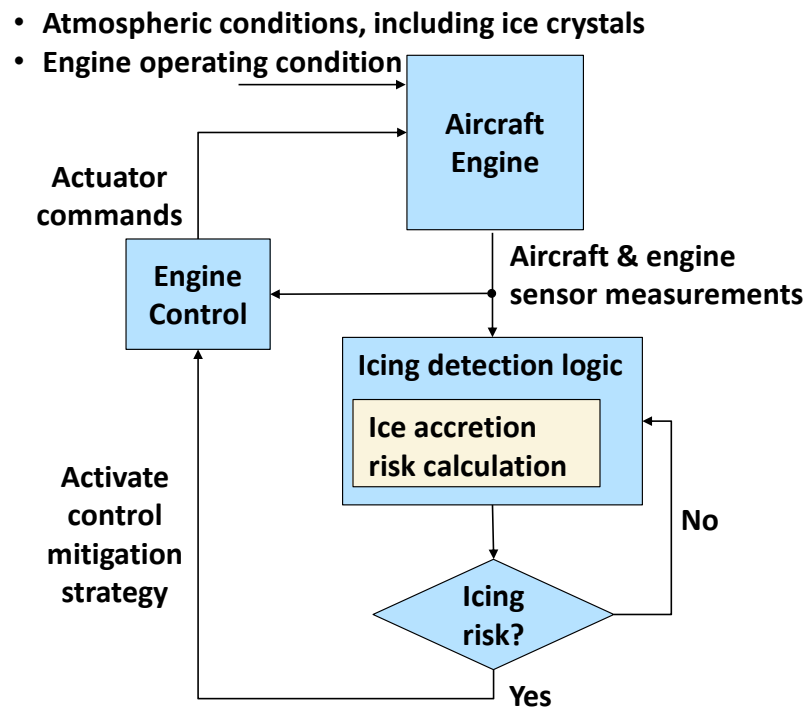

Figure 1. Active Control Icing Risk Mitigation Architecture

This paper will focus on the development of a dynamic engine model, which can serve as a surrogate for the actual aircraft engine in this architecture when conducting initial development and evaluation of icing detection and controlbased mitigation simulation studies. This model is representative of an ALF502-R5 twin-spool high bypass turbofan engine. The ALF502-R5 engine, which was originally produced by Lycoming, and then later by Allied Signal and now Honeywell, is designed for regional aircraft applications and produces approximately 7,000 pounds of thrust. NASA and Honeywell collaborated on ALF502-R5 engine ice crystal icing testing in the NASA GRC PSL facility in 2013 and 2015

This material is declared a work of the U.S. Government and is not subject to copyright protection in the United States. Approved for public release; 
[24,25]. The ALF502 engines used during PSL testing were experimental engines, with significant differences from production engines. Honeywell's participation in this testing was made possible through funding provided by the ICC.

\section{DYNAMIC MODEL DESCRIPTION}

The dynamic model of the ALF502-5R engine is a OD component level model coded using the Toolbox for the Modeling and Analysis of Thermodynamic Systems (T-MATS) [26], which is a NASA-developed open source graphical thermodynamic simulation package built in MATLAB/Simulink (The MathWorks, Inc). The developed TMATS model was derived from a Numerical Propulsion System Simulation (NPSS) model of the ALF502-5R engine using the techniques described in Ref. [27]. The NPSS ALF502-5R engine model was developed to simulate engine performance during an engine icing rollback event. The NPSS model included constructs to capture the thermodynamic effects of ice particles melting and vaporizing within the engine and a reduction in the LPC flow path area due to ice blockage buildup in the LPC. The NPSS model can be run in steady-state off design mode over a series of analysis points to simulate engine behavior during a rollback event.

Like the NPSS model described in Ref. [27], the T-MATS model includes constructs to capture the thermodynamic effects of ice water ingestion by the engine as well as ice blockage buildup within the engine's LPC. A difference between the NPSS model and the T-MATS model presented in this paper is that the T-MATS model adds the capability to simulate dynamic or transient engine behavior. It includes a fuel control system with a user selectable option to run the model in either openloop or closed-loop control mode. In addition to fuel flow, the T-MATS model also includes several auxiliary actuators, such as customer bleeds and horsepower extraction, that can be used to modulate engine operating performance. A high-level block diagram of the T-MATS ALF502-5R engine model is shown in Figure 2. Major blocks of the model include ambient conditions, inlet, fan tip, fan hub and low pressure compressor (LPC), high pressure compressor (HPC), combustor, high pressure turbine (HPT), low pressure turbine (LPT), and bypass and core nozzles.

\section{Model Inputs}

Required T-MATS ALF502-5R model inputs include ambient conditions consisting of altitude, Mach number, and dTamb (difference between actual ambient temperature and International Standard Atmosphere (ISA) temperature for the given altitude), as well as icing conditions consisting of ice particle density and the percentage of flow blockage in the LPC. Although the true percentage of LPC flow blockage that occurred during PSL testing of the ALF502-R5 engine was not measurable, a technique for calculating this model input parameter to achieve desired model-to-engine matching during rollback events has been developed, as will be described later in this paper. The user has two options for controlling the power setting of the engine. This includes open-loop control mode, in which case the user supplies commanded fuel-flow as an input, or closed-loop control mode, where the user supplies a commanded engine throttle setting (or power lever angle (PLA)).

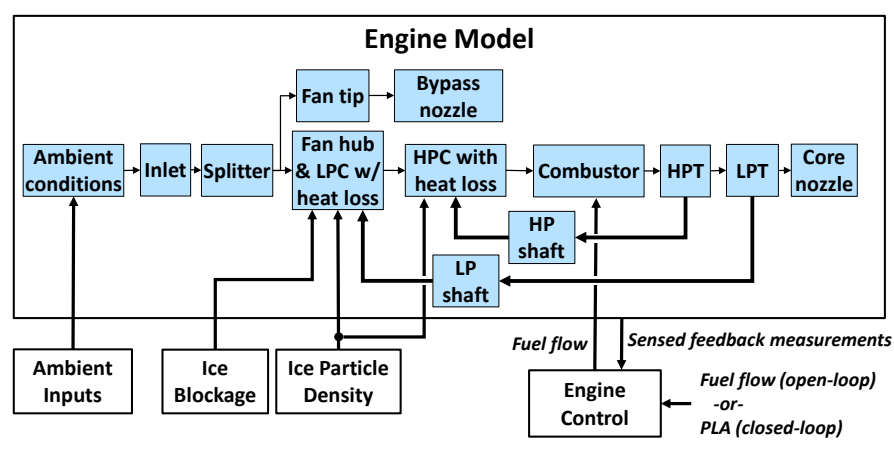

Figure 2. T-MATS ALF502-5R dynamic engine model block diagram

\section{Description of Model Turbomachinery Components}

The dynamic engine model is constructed in MATLAB/Simulink using T-MATS library building blocks. The blocks are based on basic thermodynamic equations and principles, and use a series of user-supplied maps that define the characteristics of the system being modeled. The developed T-MATS model uses the component maps applied within the NPSS model described in Ref. [27]. Numerical methods, including a Newton-Raphson iterative solver and Jacobian calculations, are also included to allow the model to be balanced to a given operating point. First order lags are added to the model's sensed temperature outputs to provide better matching with the sensor measurements acquired from the actual ALF502-5R engine during transient operation.

\section{Heat Extraction Due to Ice Particle Ingestion}

A key feature of the model is the inclusion of heat (enthalpy) extraction effects due to ice particle ingestion, which was also done for the NPSS model described in Ref. [27]. Modeling of heat extraction accounts for the phase transition that ingested ice particles undergo as they transition from iceto-water-to-vapor when passing through the engine's compression system (fan hub, LPC and HPC). For modeling purposes, this heat extraction is modeled to occur both within the LPC and the HPC as shown in Figure 3. At the exit of the LPC, heat is removed at a rate equal to the amount required to raise the ice temperature from the inlet temperature condition to $32^{\circ} \mathrm{F}$, melting the ice, and then further raising the water temperature to the LPC exit temperature. Here, the heat loss rate, $Q_{L P C}$, is calculated as

$$
Q_{L P C}=w_{i c e} c_{i c e}\left(32^{\circ} F-T 2\right)+w_{i c e} H_{f}+w_{\text {ice }} c_{\text {water }}\left(T 25-32^{\circ} F\right)
$$

where $w_{i c e}$ is the ice mass flow rate entering the core of the engine, $c_{i c e}$ is the specific heat of ice, $c_{\text {water }}$ is the specific heat 


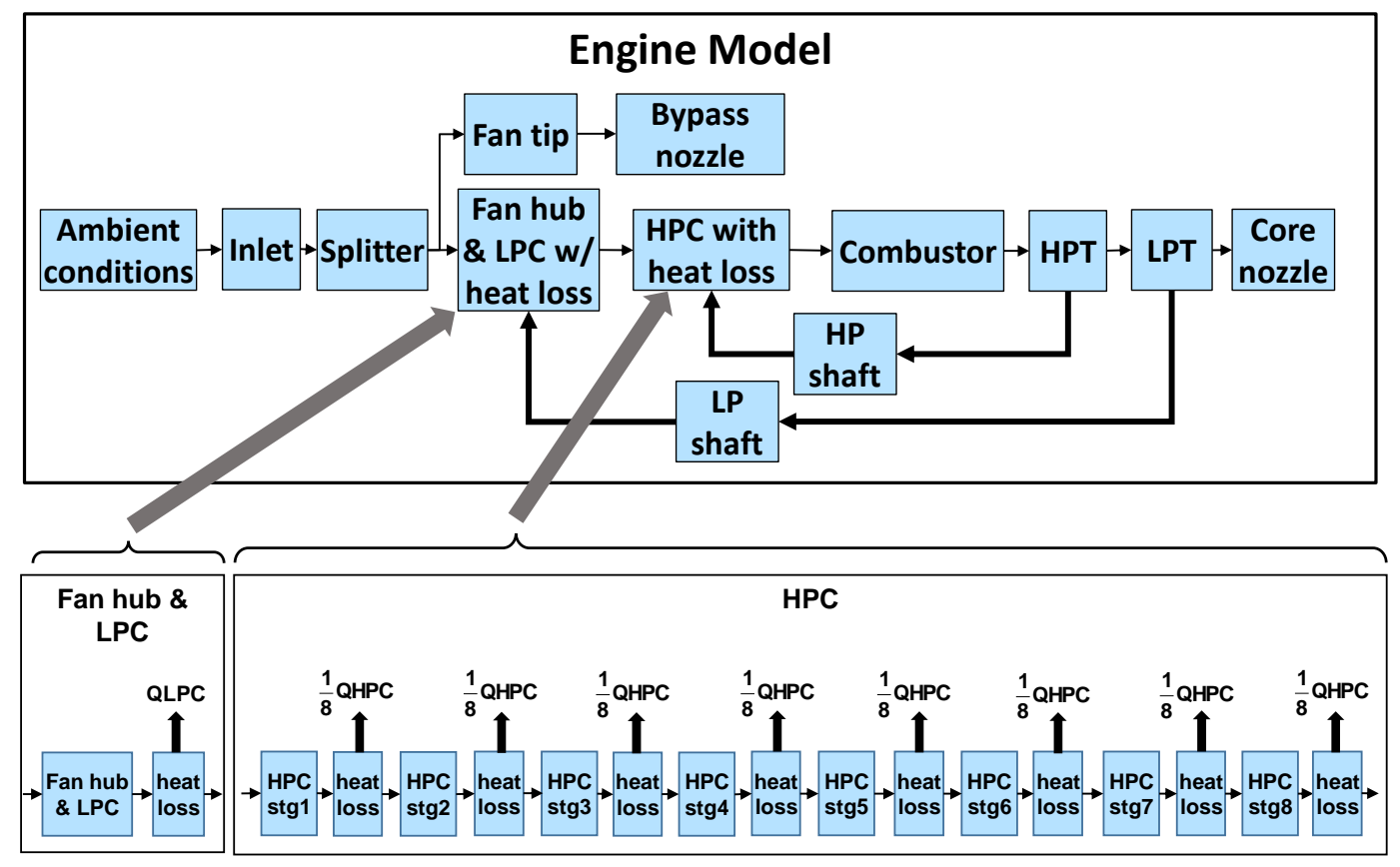

Figure 3. Implementation of heat loss in compression system

of water, $H_{f}$ is the heat of fusion of ice, T2 is the inlet temperature, and T25 is the LPC exit temperature.

The HPC of the ALF502-5R engine is an eight-stage design consisting of seven axial stages and one centrifugal stage. As shown in Figure 3, within the model the HPC is implemented as eight individual T-MATS compressor blocks, each representing a single stage of the HPC. A performance characteristic map for each HPC stage similar to a single stage fan was used, and each stage was assumed to have the same polytropic efficiency and specific work. After each stage, a portion of the total heat extraction within the HPC is performed. The model first calculates the heating rate required to raise the liquid from the HPC inlet temperature to boiling temperature, vaporizing it, and then further heating the vapor to the HPC exit temperature. This is given as

$$
\begin{gathered}
Q_{H P C}=w_{\text {ice }} c_{\text {water }}\left(212^{\circ} F-T 25\right)+w_{\text {ice }} H_{v} \\
+w_{\text {ice }} c_{\text {steam }}\left(T 3-212^{\circ} F\right)
\end{gathered}
$$

where $c_{\text {water }}$ and $c_{\text {steam }}$ are the specific heat of water and steam, respectively, and $H_{v}$ is the heat of vaporization of water. This heat loss is then removed from the HPC stage-by-stage in eight equal increments, with the total heat loss rate summing to the amount given in Eq. (2).

For the engine icing rollback events demonstrated during PSL testing, the mass flow rate of ice ingested into the engine was relatively small-approximately $0.5 \%$ that of air. This additional mass of ingested ice is not accounted for in the model calculations. Other parameters such as heat transfer from the air to the water vapor past the HPC component and heat transfer through metal components are also neglected in the model.

\section{Flow Blockage Due to Ice Buildup in the LPC}

The ALF502-R5 T-MATS model includes an "LPC ice blockage" input, a lumped parameter that captures LPC performance changes occurring from ice accretion. At the cycle level, the impact of this input is on LPC pressure ratio, air flow, and efficiency. In the model, ice blockage buildup within the LPC of the engine is captured through a series of modified LPC maps, each representing a different amount of flow blockage in the LPC. These maps are generated using a NASA-developed mean-line compressor design code (COMDES) [28], where a reduction in the LPC flow path area was added, to simulate the effect of ice blockage as described in Ref. [29]. Using this code, the size of the blockage can be changed and a new compressor map developed. This results in a series of maps that can be "stacked" and interpolated between to enable the simulation of an arbitrary ice blockage level. By changing the "LPC ice blockage" input parameter the user can simulate the accretion of ice crystals and flow blockage within the engine.

\section{Open-Loop versus Closed-Loop Control of Engine Model}

The user has two options for controlling the thrust output of the ALF502-R5 T-MATS model. The first option is to run the model in open-loop control mode while supplying a time history of fuel flow, Wf, which is directly fed into the model's combustor block. The second option is to run the model in closed-loop control mode, consistent with how the engine was 
operated during PSL testing. Here, as opposed to a fuel flow input, the user supplies a time history of power lever angle (PLA). Within the model's closed-loop control logic, the provided PLA input is converted to a commanded engine power setting. In the T-MATS ALF502-5R engine model's control logic, this is implemented by converting the supplied PLA input into a corresponding Wf/P3 vs. N2 characteristic line, known as an N2 governor droop line [30]. Here, Wf/P3 is the ratio of fuel flow to HPC exit pressure, P3, and N2 is core speed. A notional depiction of the $\mathrm{N} 2$ governor droop line plotted in Wf/P3 vs. $\mathrm{N} 2$ parameter space is shown in Figure 4a. The location of the N2 governor droop line changes in response to changes in PLA. Also plotted in this figure is the engine's own characteristic operating line. The location of the engine's operating line is dependent on various factors such as the engine's deterioration level, bleed extractions, heat transfer due to ice particle ingestion, and ice buildup in the engine. The intersection of the N2 governor droop line and the engine operating line defines a point of steady-state operation, and the model's fuel control logic applies a proportional-integral controller to adjust fuel flow to run the model to this operating point. As shown in the figure, the engine model can be run to higher or lower power settings on the engine operating line by increasing or decreasing the provided PLA input. As previously noted, ice buildup within the compression system changes the flow characteristics of the compressor, shifting the engine's operating line. Figure $4 \mathrm{~b}$ shows a notional depiction of how the engine's operating line shifts upward due to ice particle ingestion and ice blockage, which results in a corresponding control adjustment of fuel flow to maintain engine operation on the N2 governor droop line. As described in Ref. [30], during ice blockage induced engine rollback events, the engine operating point will move upwards along the $\mathrm{N} 2$ governor droop line. While the actual ALF502-5R engine includes additional control limit logic, these limits are not encountered until a significant amount of ice buildup has occurred and the engine is relatively far into an icing rollback event. Since the intent of the model presented in this paper is for the development and evaluation of approaches for the incipient detection and mitigation of engine icing events, such limit logic is not included in the T-MATS model presented in this paper.

\section{Auxiliary Actuators}

In addition to fuel flow, several additional actuators are included in the T-MATS engine model. This includes two customer bleeds, an anti-ice bleed, and horsepower extraction. Figure 5 shows the location of each actuator within the engine model. When opened, the fan customer bleed and core customer bleed extract a fraction of the airflow aft of the fan tip and the HPC, respectively. The anti-ice bleed also extracts airflow aft of the HPC exit. Additionally, the anti-ice bleed causes an enthalpy change in the airflow entering the fan hub and LPC. Horsepower extraction results in a reduction in the torque of the model's high pressure shaft.

The intent of including these additional auxiliary actuators in the model is to evaluate how their modulation changes the engine operating point, and how that change in operating point effects the engine's risk of ice accretion and thrust output. Although not evaluated in this paper, follow-on work will couple the engine model with an icing risk calculation tool developed by NASA GRC (see Ref. [23]) to enable this evaluation.

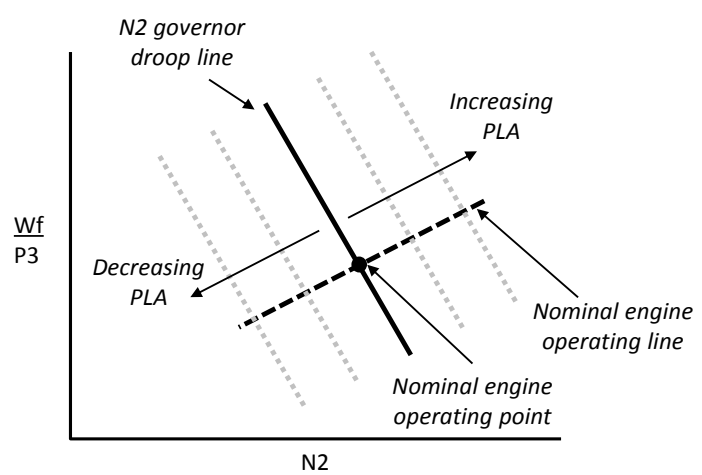

a) Movement of N2 governor droop line with changing PLA

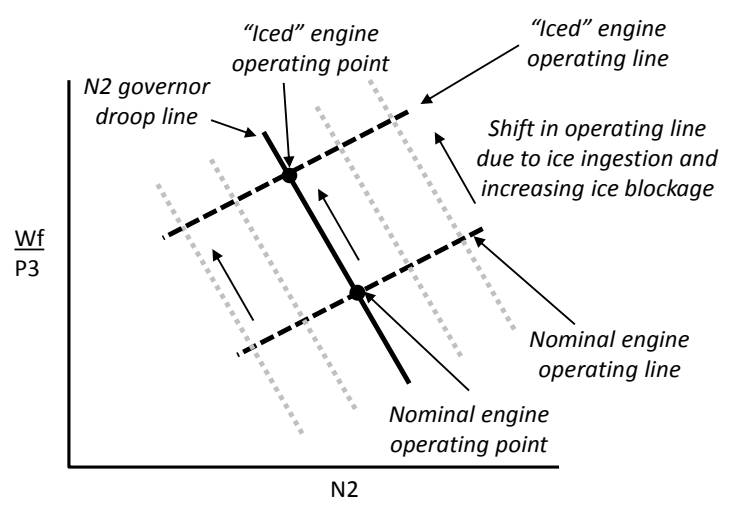

b) Movement of engine operating line caused by heat transfer due to ice ingestion and increasing ice blockage

Figure 4. Engine N2 governor droop line control

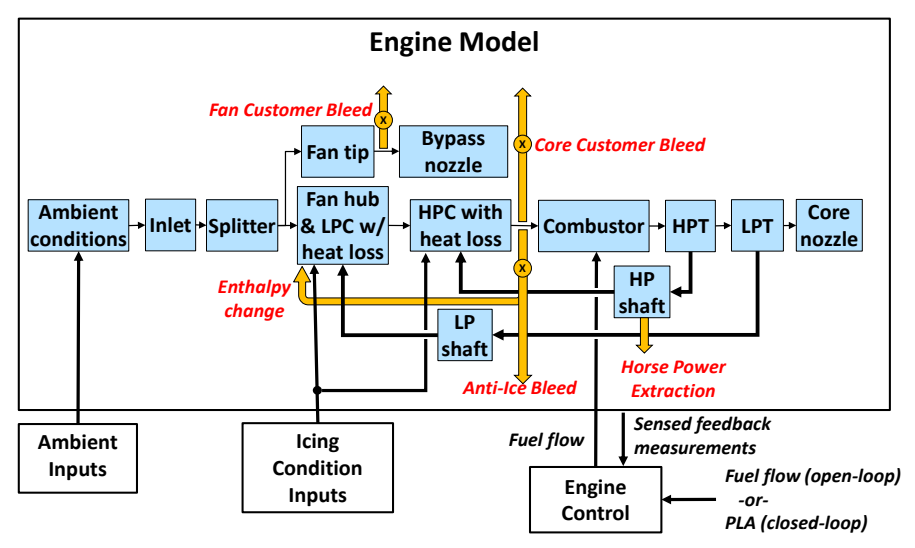

Figure 5. Dynamic Engine Model - Auxiliary Actuator Locations 


\section{MODEL COMPARISON TO EXPERIMENTAL RESULTS}

Recently, two experimental (non-production) ALF502-5R engines underwent ice crystal icing tests in the PSL at the NASA Glenn Research Center. The first test, conducted on engine serial number LF01, occurred in 2013 [24], and the second test, conducted on engine serial number LF11, occurred in 2015 [25]. During this testing, the engines were subjected to ice crystal ingestion and multiple engine rollback events were demonstrated. In this paper, experimental data recorded from the LF01 engine test will be compared against the developed TMATS engine model.

\section{NASA GRC PSL Facility and Ice Crystal Engine Testing}

The NASA GRC PSL is an altitude simulation facility for experimental research on air-breathing propulsion systems [31]. There are two test cells within the facility, PSL-3 and PSL-4, which are capable of providing simulated flight conditions to altitudes in excess of 90,000 feet. In 2012, PSL-3 was modified to include a water spray nozzle array system to produce ice crystal clouds at simulated altitudes during aircraft engine testing [17,32]. Photos of the spray nozzle system and the installation of the LF01 engine in PSL-3 are shown in Figure 6.
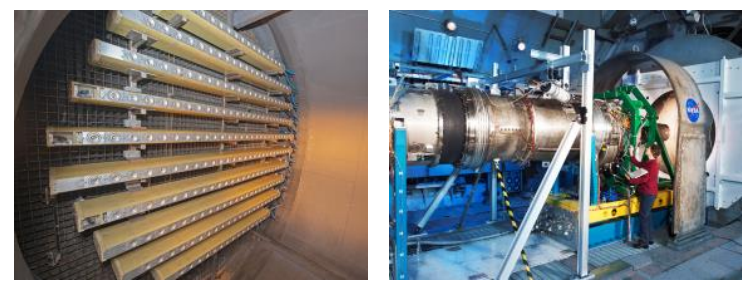

Figure 6. Water injection spray nozzles and LF01 engine installation in PSL-3

The 2013 LF01 engine test in PSL-3 marked the inaugural engine icing test conducted in the facility. Objectives of this test were to validate that the newly modified test cell could be calibrated and operated at target flight test conditions, and to duplicate documented thrust rollback events that occurred during revenue service. During LF01 testing in PSL-3, multiple engine rollback events were successfully induced. Figure 7 shows engine performance parameter measurements recorded during the first engine rollback event demonstrated during LF01 PSL-3 engine testing, denoted as Run 193*. This test was conducted at an operating point of approximately 28,000 feet, $0.5 \mathrm{Mach}$, and $+28^{\circ} \mathrm{F}$ dTamb. Shown are the first 200 seconds of recorded measurements for fan speed, N1, core speed, N2, HPC exit pressure, P3, HPC exit temperature, T3, exhaust gas temperature, T45, fuel flow, $\mathrm{Wf}$, and the ratio of fuel flow to HPC exit pressure, Wf/P3. Due to the proprietary nature of the data, here and throughout the remainder of this document, yaxis units are normalized to show fractional units relative to each parameter's stabilized operating condition prior to the ice

\footnotetext{
${ }^{*}$ Run number denotes the facility data acquisition system recording number for a given LF01 PSL-3 engine test run.
}

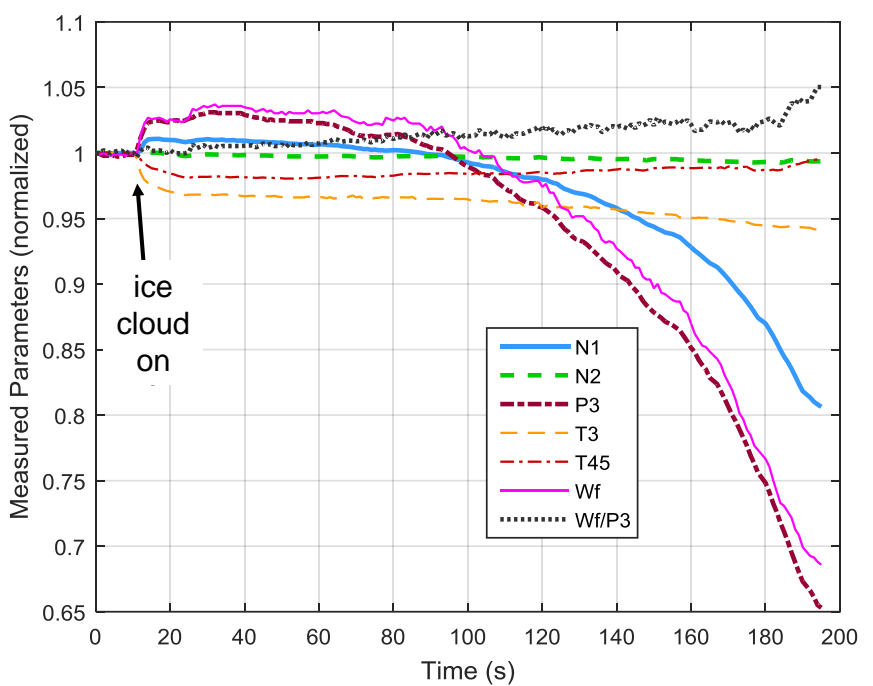

Figure 7. Normalized engine measurement parameters recorded during LF01 Run 193 rollback event

cloud turning on. During the test, engine power setting was first stabilized at the target operating condition and then the ice cloud was turned on. This occurs at 10 seconds, and is evident from the step change in several of the parameters that occurs at this time. As ice blockage builds up in the engine, the uncommanded rollback event ensues. This is most apparent in $\mathrm{N} 1, \mathrm{P} 3$, and $\mathrm{Wf}$, which exhibit a noticeable reduction relative to their pre-ice cloud readings.

\section{Comparison of Engine Model to LF01 Engine Experimental Data}

Experimental measurement data acquired during LF01 engine testing was used to evaluate the T-MATS ALF502-5R engine model's ability to capture engine dynamic behavior during icing events. The engine model was run under both open-loop and closed-loop control operating modes, and the model's output was compared against sensed measurement outputs acquired from the engine. Recorded parameters of altitude, Mach, dTamb, Wf (open-loop only), and PLA (closedloop only) were supplied as inputs to the model. Additional model input parameters of ice particle concentration and LPC flow blockage were determined based on the experimental data. The subsections below will present the steps for calculating and supplying these inputs to the T-MATS ALF502-5R engine model. A comparison of model and experimental results will first be shown for LF01 PSL-3 Run 193, followed by a comparison of the results for additional LF01 engine rollback events.

Calculation of Ice Particle Concentration. The fundamental research conducted during the LF01 PSL-3 testing included assessing engine response when subjected to ice cloud conditions of varying total water content and particle mean volumetric diameter (MVD). Throughout the test, the water flow rate supplied to the spray nozzle array and the airflow rate entering the engine was recorded. This information was used to

This material is declared a work of the U.S. Government and is not subject to copyright protection in the United States. Approved for public release; 
calculate the ice particle density input supplied to the T-MATS ALF502-5R engine model.

Figure 8a shows an example of the calculated ice particle concentration for the LF01 PSL-3 Run 193 engine rollback event. It should be noted that ice particle density is affected by the direct connect nature of the PSL test set-up [24]. While the total water flow rate supplied to the spray nozzles was held constant when an ice cloud was on, the total airflow into the engine would reduce as the engine rolled back. This causes an increase in ice particle concentration as the engine progresses further into rollback.

Figure $8 \mathrm{~b}$ shows the initial drop in LF01 HPC exit temperature, T3, for the same PSL test run when the ice cloud turned on. As previously described, this temperature drop is hypothesized to be due to heat loss effects caused by the melting and vaporization of ice particles as they pass through the engine's compression system. Also shown in the figure is the T-MATS model produced T3 output under two scenarios. First, when the model is supplied the calculated ice particle density input parameter given in Figure 8a, and then when this same model input parameter is set to zero. Setting this input to zero is equivalent to running the model without heat loss effects. The results show that including heat loss effects is necessary in order to accurately capture the initial drop in T3.

In evaluating different run cases from the LF01 PSL-3 testing, it was found that the model's ability to accurately match the magnitude of the measured T3 drop that occurred when the ice cloud was turned on varied by run case. The testing did evaluate engine response to different water spray patterns and MVD conditions, which possibly contributed to these variations. Given this finding, the calculated ice particle concentration input supplied to the model was adjusted by a scale factor that results in the model producing the same drop in T3 as was observed in the LF01 test engine T3 measurement data for a given run case. The magnitude of the ice particle concentration scale factors applied for the various engine rollback events evaluated in this study ranged from 0.86 to 1.05. For Run 193 specifically, a scale factor of 0.88 was applied.

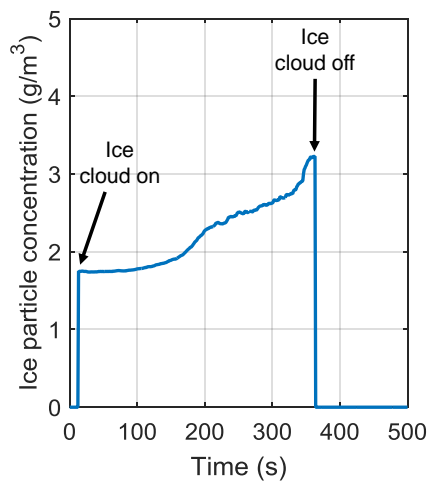

a) Calculated ice particle density

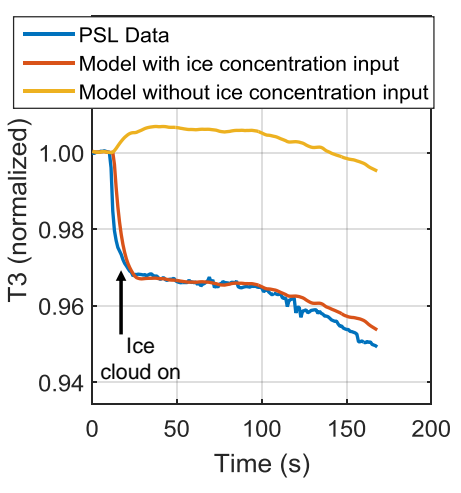

b) Engine and model $\mathrm{T} 3$ response
Figure 8. Calculated ice particle density and $\mathrm{T} 3$ response during the Run 193 engine rollback event
Calculation of the amount of LPC Ice Blockage. The engine rollback events demonstrated during LF01 PSL-03 testing confirm that some amount of ice buildup was occurring within the engine's compression system. However, there was no means of directly measuring the actual amount, or percentage, of LPC flow blockage. In order to estimate the amount of LPC ice blockage, which is a necessary model input, an automated technique was developed and applied. This technique estimates the ice blockage buildup time history that will produce the same rollback rate in $\mathrm{N} 2$ within the model as was observed within the actual N2 measurement data recorded from the engine. To make this calculation, a two-dimensional table lookup model was constructed that produces an estimate of the amount of LPC ice blockage given inputs of fuel flow and the $\mathrm{N} 2$ error between the engine and the model run with no LPC ice blockage. The table lookup model was constructed by running the model in open-loop control mode at fixed altitude, Mach number, dTamb, and ice particle concentration inputs while varying fuel flow and \% LPC ice blockage over a range of discrete settings and storing the corresponding change in N2. The resulting data is applied within the table lookup model, and linear interpolation is used to retrieve values between grid points. Once the table lookup model was created, the engine model was run in a three-step process. First, the model was run open-loop and provided all necessary inputs except for the amount of LPC flow blockage, which is set to zero. Then, the resulting error between the model's N2 output and the desired $\mathrm{N} 2$ to produce the same $\mathrm{N} 2$ rollback rate as that observed in the engine was calculated. This $\mathrm{N} 2$ error along with the measured fuel flow from engine testing were then supplied as inputs to the lookup table to retrieve an LPC ice blockage history. Finally, this blockage, along with the other original inputs, was supplied as inputs to the model. Figure 9a shows an example of the calculated amount of LPC ice blockage for the LF01 PSL-3 Run 193 rollback event, and Figure 9b shows the corresponding $\mathrm{N} 2$ response for the engine and the model run with and without this LPC ice blockage input. The case without blockage input is equivalent to the initial calibration run conducted to determine the N2 value without any ice blockage (i.e., first step in the

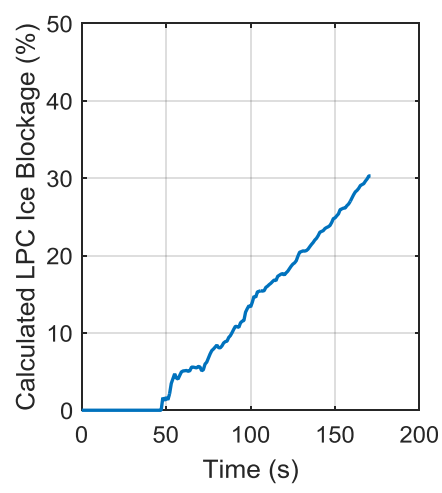

a) Calculated LPC ice blockage

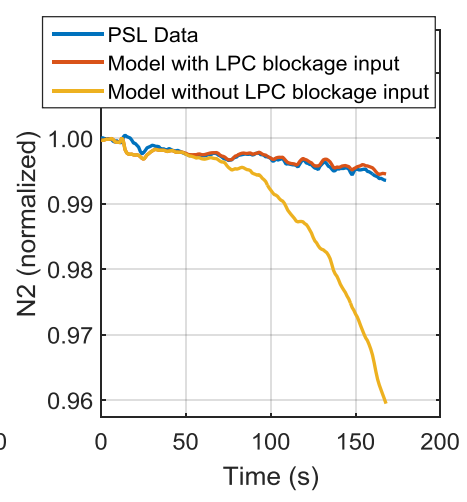

b) Engine and model N2 response
Figure 9. Calculated LPC ice blockage and N2 response during the Run 193 engine rollback event

This material is declared a work of the U.S. Government and is not subject to copyright protection in the United States. Approved for public release; 
three-step process of simulating a rollback event). Without ice blockage input, the model's N2 response rolls off more rapidly than what occurs in the actual engine. It is emphasized that the calculated amount of LPC ice blockage should not be interpreted as a true measure of the amount of blockage within the LPC. Instead, this is simply the amount of blockage input necessary for the model's N2 output to follow the same rollback rate as that observed in the engine's N2.

Modeling of Run 193 Engine Rollback Event. The Run 193 rollback event was simulated by running the T-MATS ALF502-5R engine model in both open-loop and closed-loop control mode. The applied model input parameters are shown in Figure 10a. These inputs include ice concentration and LPC ice blockage inputs (calculated as described in the previous subsections) plus an additional model input (based on PSL recorded data) of either fuel flow or PLA dependent on whether the model is run in open-loop or closed-loop control mode, respectively. Figure 10b compares model-produced outputs against the engine sensed outputs recorded during the PSL testing. These outputs include N1, N2, P3, T3, T45, and Wf. For the fuel flow parameter, open-loop fuel flow is omitted as this parameter is identical to PSL recorded fuel flow. Also shown in Figure 10b is the T25 output produced by the model. While T25 was not recorded during the test, this modelproduced output is shown to illustrate it's response during the simulated rollback event.

The model is found to perform reasonably well in matching the response of PSL recorded engine data. This includes capturing the initial step changes in engine outputs that occur at the time the ice cloud turns on, and the engine rollback event that ensues. Here, data are only plotted up to the point in time when the model fails to converge and terminates execution due to operation moving outside defined component map boundaries. The LF01 engine tested in PSL actually ran further into rollback, but that data is not plotted here. Furthermore, the current capability of the model to capture the initial onset of rollback events is deemed sufficient for its intended purpose of enabling the development of approaches for the incipient detection and mitigation of engine icing events. The ability of the model to accurately capture engine behavior further into a rollback event is not essential.

Good agreement between the initial T3 step decrease in the engine and model data is shown, which is expected as the ice particle concentration input is scaled to produce an equivalent response in T3. Similarly, good agreement in the N2 slope decrease of the engine and the model was shown, which is also expected since the LPC \% ice blockage is defined to produce this result. The encouraging result is that the remaining model outputs, including N1, P3, T45, and Wf, all track engine data reasonably well. The agreement between the model and the data in Wf is particularly noteworthy as it confirms that the developed model's closed-loop controller is able to reasonably emulate the actual engine's fuel controller. The step decrease in model-produced T25 outputs that occurs when the ice cloud turns is due to heat removal at the LPC exit (see Eq. (1)).
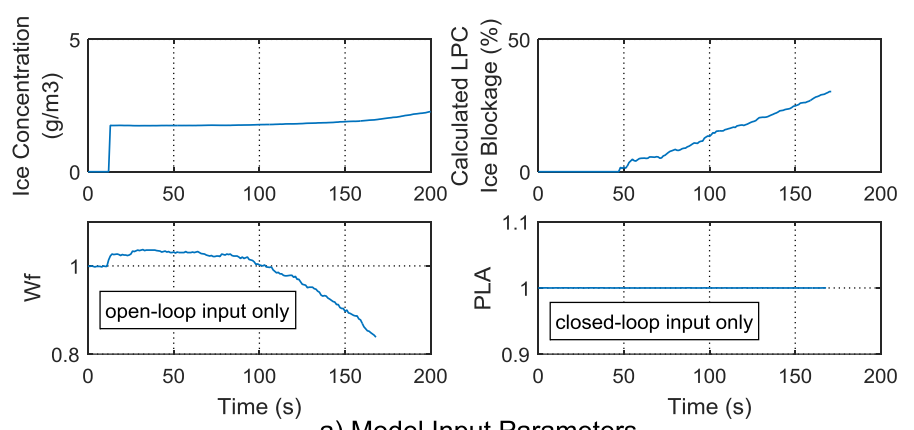

a) Model Input Parameters
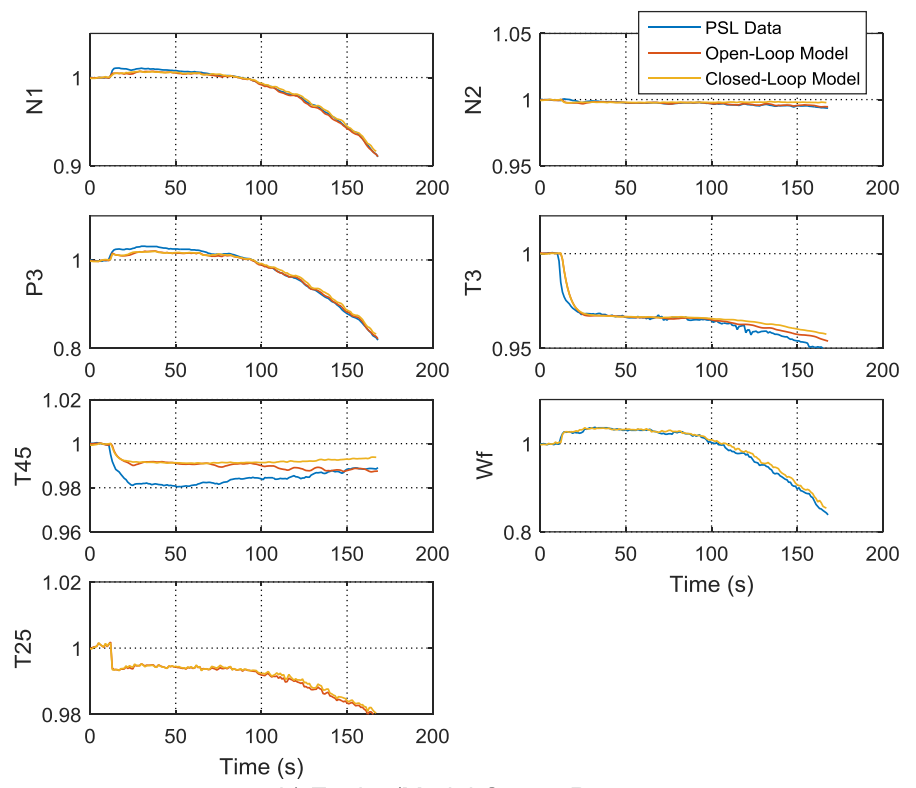

b) Engine/Model Output Parameters

Figure 10. Input and output parameters for Run 193 engine rollback event

Modeling of Additional Engine Rollback Events. In addition to Run 193, four other LF01 rollback events demonstrated in PSL-3 were selected for comparison against the developed T-MATS ALF502-5R engine model. These events include Run 199, Run 206, Run 570, and Run 940. Like Run 193, these rollback events were each conducted at an operating point of approximately 28,000 feet, 0.5 Mach, and $+28^{\circ} \mathrm{F}$ dTamb. Model input parameters for the five run cases are shown in Figure 11. Here, ice particle concentration and calculated ice blockage inputs are calculated following the procedure described earlier in the paper. The scale factors applied to the model's ice particle concentration inputs for the five cases were 0.88 (Run 193), 1.05 (Run 199), 0.90 (Run 206), 0.99 (Run 570), and 0.86 (Run 940). In comparing the ice particle concentrations, it can be observed that the magnitude and the duration of ice particle concentrations varied by run case. Runs 193 and 940 had the highest ice particle concentrations, followed by run 206 at an intermediate concentration level, and runs 199 and 570 at the lowest levels.

The input parameters for the various run cases were supplied as inputs to the model while operating the model in 
both open- and closed-loop control mode. Figure 12 compares model produced outputs against corresponding engine sensed outputs recorded during the PSL testing. Better agreement between engine and model outputs are found for runs 193, 199, and 206, while runs 570 and 940 show noticeable bias offsets between the engine and model. As described in Ref [24], LF01 flow path hardware did experience damage during PSL testing. This is suspected to be a result of ice sheds impacting rotating hardware. Runs 193, 199, and 206, which were the first three engine icing rollback events demonstrated during the LF01 PSL test, occurred prior to the occurrence of this shedding damage while Runs 570 and 940 were conducted after the damage had occurred. For each of the test runs, the test commenced at the same target N1 speed, but a higher PLA setting and increased fuel flow (see Figure 11) was required to achieve this same target N1 speed once the engine had experienced damage. The developed T-MATS ALF502-5R model does not currently have any inputs that allow for directly adjusting component performance to reflect such degradation, and consequently the model does not match the engine as well for runs 570 and 940.

\section{Comparison of Engine Model to Customer Deck}

In follow-on studies, the developed engine model will be used to evaluate the feasibility of control-based strategies for mitigating the risk of engine icing. This will entail modulation of the model's auxiliary actuators and assessing the corresponding impact on icing risk. With the exception of the anti-ice bleed valve, the auxiliary actuators included in the TMATS ALF502-5R engine model were not modulated during the LF01 PSL engine testing. Given that engine test data was not available for assessing the correct implementation of these actuators in the model, the authors opted to use outputs from a Honeywell provided customer deck of the ALF502-5R engine. The Honeywell customer deck produces steady-state engine outputs at user specified flight conditions and engine operating settings, and also permits the modulation of the four auxiliary actuators included in the T-MATS model. To conduct this comparison, the customer deck was first run to a flight condition of 28,500 feet, 0.5 Mach number, and dTamb $=28^{\circ} \mathrm{F}$ while fuel flow was held constant. Next, the customer deck was re-run at the same operating condition and fixed fuel flow setting while individually modulating the four auxiliary actuators. The corresponding percent change in select engine outputs due to the modulation of each actuator was recorded. The T-MATS model was then run to the same flight condition and its actuators are individually modulated while operating the model in open-loop control mode and holding fuel flow constant. The T-MATS model and the customer deck were then
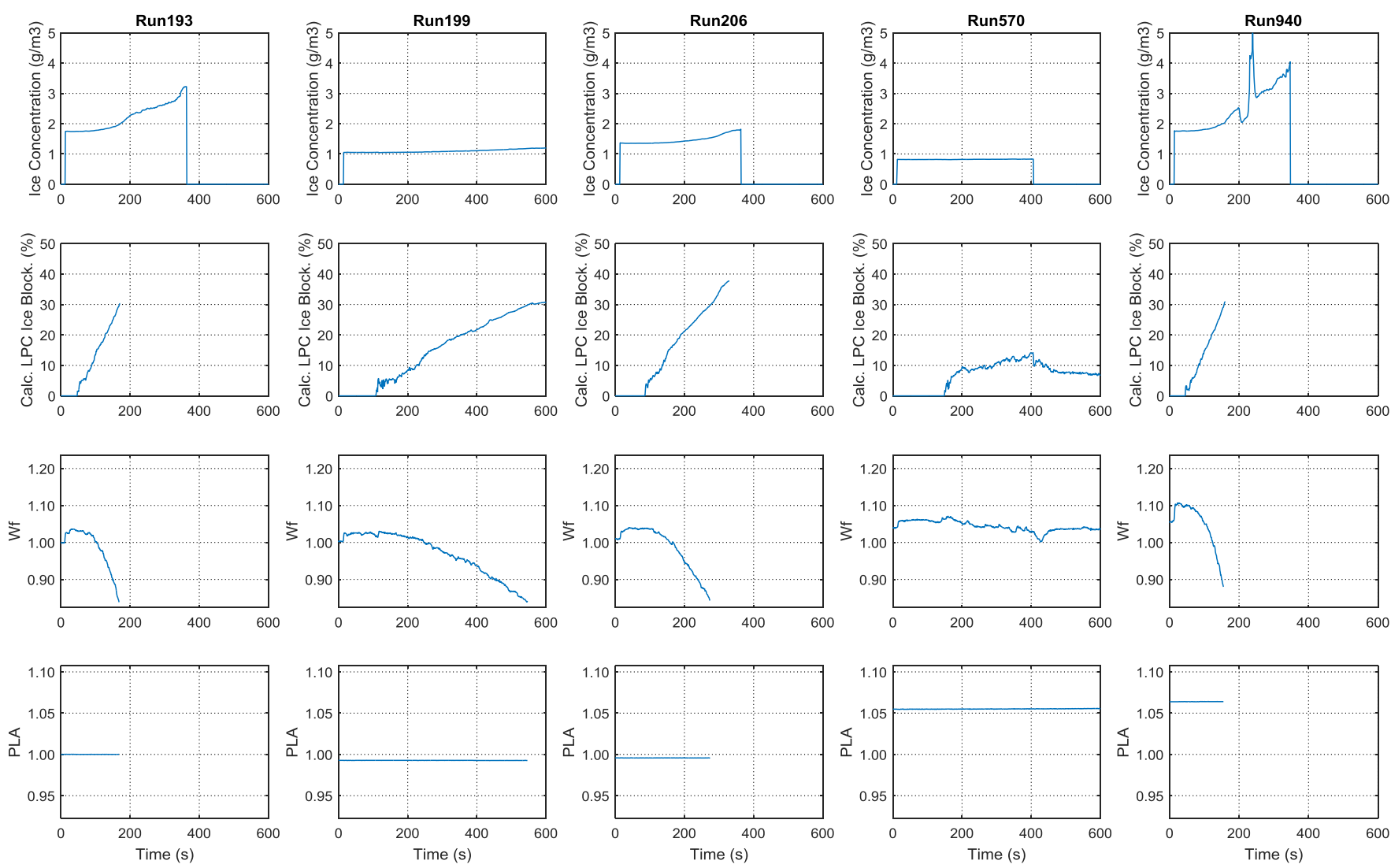

Figure 11. Model input parameters for five engine rollback events. Ice concentration and LPC ice blockage are provided as model inputs for both the open-loop and close-loop run cases, while Wf is only provided as a model input for the open-loop run case and PLA is only provided as a model input for the closed-loop run case.

This material is declared a work of the U.S. Government and is not subject to copyright protection in the United States. Approved for public release; distribution is unlimited. 

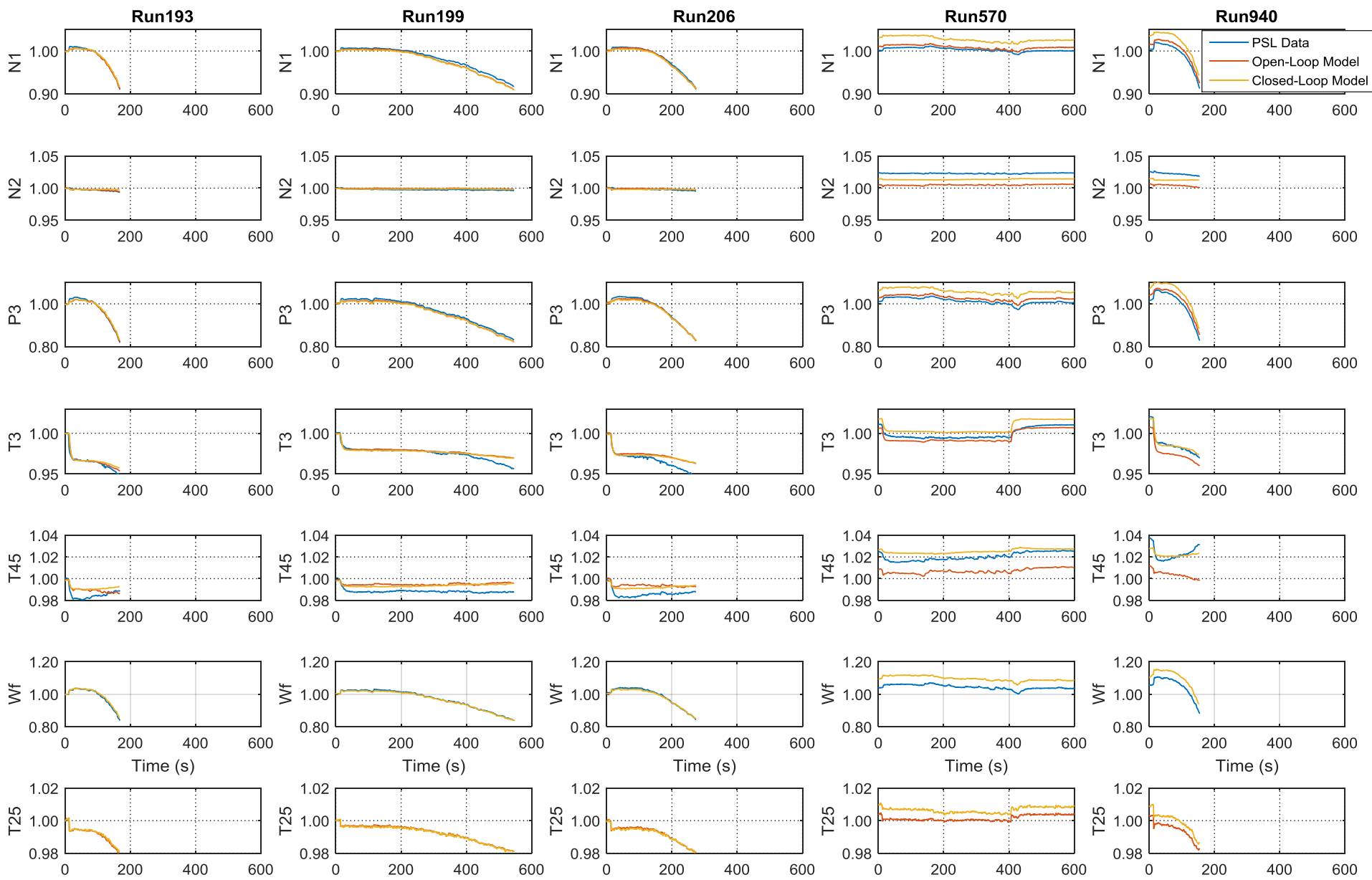

Figure 12. Engine and model output parameters for five engine rollback events

re-run under closed-loop control, and the modulation of actuators was repeated. For this evaluation, the T-MATS model was operated in closed-loop control mode with a fixed PLA input. For the customer deck, which does not provide direct closed-loop control operating capability, closed-loop operation was emulated by manually adjusting fuel flow to achieve operation on the $\mathrm{N} 2$ governor droop line. Results comparing the percent change in model outputs for the four actuators are shown in Figure 13. Output parameters shown include rotor speeds, fuel flow, and select pressures, temperatures, and air flow parameters at various stations of the model. The results show that the T-MATS model implementation of the actuators provides good agreement with the customer deck produced outputs, confirming the implementation of the actuators within the T-MATS model. In particular, the closed-loop results reflect the change in engine performance that can be expected when modulating the various actuators while the engine is operating under closed loop-control, as it would be during actual flight operation. As such, this provides information that will be used as part of planned follow-on studies that will assess the engine icing risk reduction achievable through modulation of available control actuators.

\section{DISCUSSION}

The T-MATS ALF502-5R engine model has been shown to emulate engine system-level behavior during ice crystal icing tests conducted in the NASA GRC PSL facility and the steadystate outputs of the manufacturer's customer deck. This model will be used as part of follow-on research focused on the development and evaluation of engine icing risk detection and control-based mitigation strategies. Detection strategies based on both conventional and advanced sensor measurements will be considered. This includes monitoring for ambient conditions of known engine icing risk coupled with an observed change in engine measurements indicative of ice particle ingestion (see Figure 7). Advanced sensors may include aircraft forward looking sensors capable of detecting airborne ice crystals and/or engine mounted sensors capable of detecting engine metal temperature changes or the accretion of ice on engine 

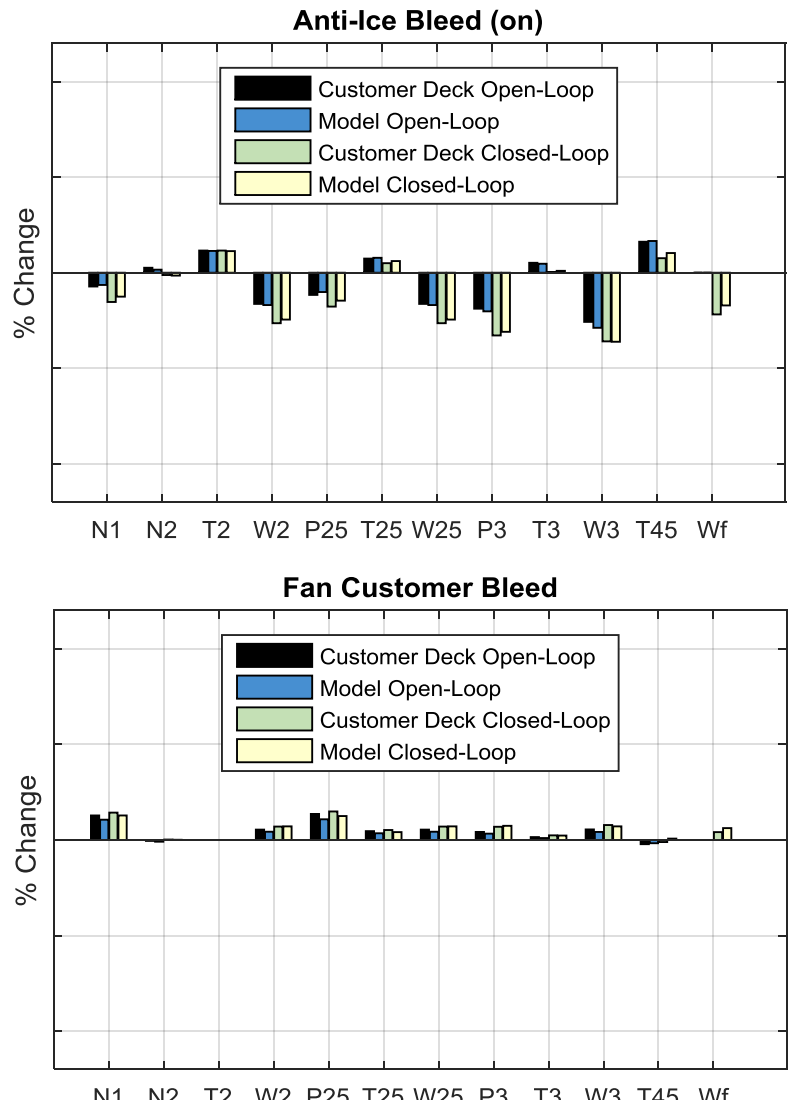

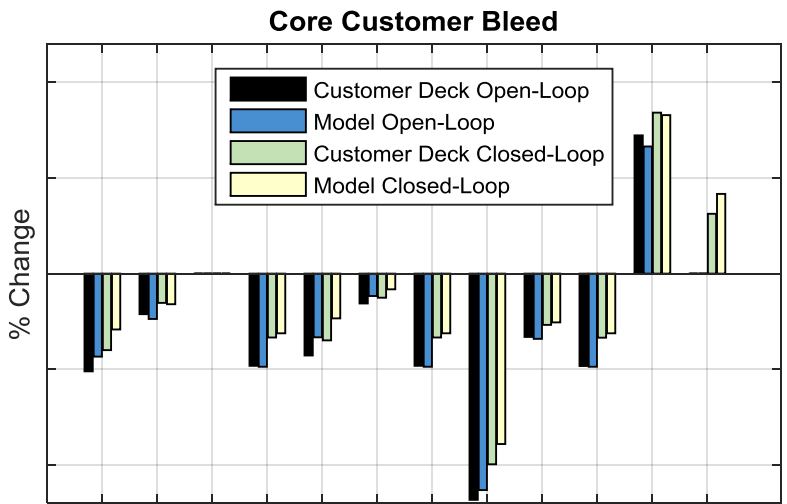

$\begin{array}{lllllllllll}\text { N1 } & \text { N2 } & \text { T2 } & \text { W2 } & \text { P25 } & \text { T25 } & \text { W25 } & \text { P3 } & \text { T3 } & \text { W3 } & \text { T45 }\end{array}$

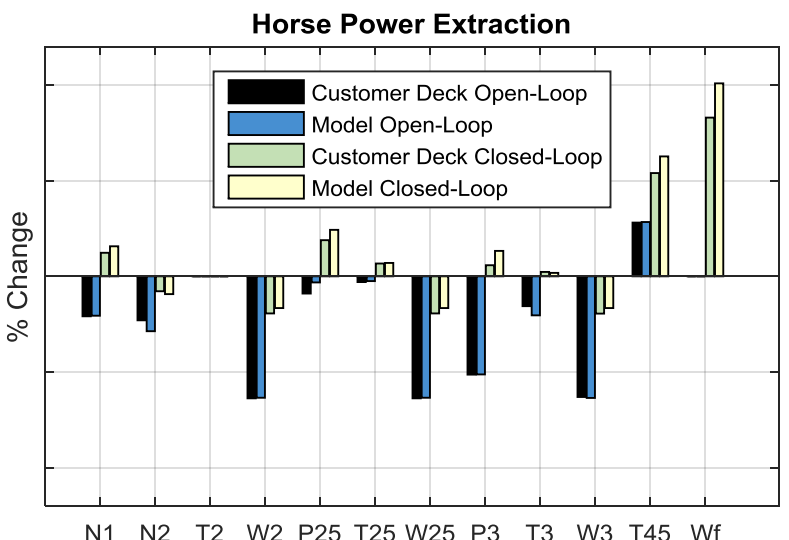

Figure 13. Model steady-state change to actuator modulation

components. Detection techniques that offer high reliability (limited false alarms and missed detections) and incipient detection capability prior to any appreciable ice accretion are key requirements. The mitigation research will couple the model with an icing risk assessment tool to allow the benefit of control-based icing mitigation strategies to be assessed. This work will include sensitivity studies to quantify the icing risk reduction offered by the modulation of available engine actuators as well as the development and evaluation of controlmitigation logic. In developing control-based icing risk mitigation approaches, simplistic solutions will be sought which do not compromise the engine's ability to deliver requested thrust output. As part of the follow-on work, additional fidelity will be added to the LPC of the model to capture the stage-by-stage operating characteristics of the module and allow the risk of ice accretion within each stage to be shown. The follow-on assessment will initially consider the baseline N2 droop line governor fuel controller and the current suite of actuators included in the model. Additionally, alternative fuel control strategies, such as fan speed control, will be evaluated for their robustness or susceptibility to icing risk, and additional actuators will be evaluated for their benefit of reducing the risk of engine icing.

\section{SUMMARY}

A dynamic model of the ALF502-5R engine has been developed and shown to emulate engine system-level behavior during ice crystal icing test cell evaluations as well as the steady-state outputs produced by the manufacturer's customer deck. Heat extraction effects are included in the compression system of the model to reflect the heat loss the engine experiences as ingested ice crystals transition from ice, to water, and vapor. Additionally, the model matches system-level engine effects as ice buildup occurs within the engine's low pressure compressor. The model will be used in follow-on studies to develop and evaluate icing risk control-based mitigation strategies.

\section{ACKNOWLEDGMENTS}

This work was conducted under the NASA Advanced Air Vehicles Program, Advanced Air Transportation Technologies Project. The authors graciously acknowledge the support of Ryan May and Jeff Chapman in developing the model. The authors also wish to thank Honeywell Engines and the Ice Crystal Consortium for their support of the engine testing that enabled this work. 


\section{REFERENCES}

[1] Mason, J. G., Strapp, J. W., Chow, P., (2006), "The Ice Particle Threat to Engines in Flight," AIAA 2006-206, 44th AIAA Aerospace Sciences Meeting and Exhibit January 9-12, Reno, Nevada.

[2] Mason, J. G., Grzych, M. L., Chow, P., (2008), "Current Perspectives on Jet Engine Power Loss in Ice Crystal Conditions: Engine Icing," in Seventh AIRA Research Implementation Forum Boeing.

[3] Mason, J. G., (2007), "Engine Power Loss in Ice Crystal Conditions," AERO. Vol. Qtr. 4, The Boeing Company, Seattle, WA, pgs. 12-17.

[4] Bravin, M., Strapp, J. W., and Mason, J. G., (2015), “An Investigation into Location and Convective Lifecycle Trends in an Ice Crystal Icing Engine Event Database," SAE 2015 International Conference on Icing of Aircraft, Engines, and Structures, SAE Technical Paper 2015-012130.

[5] Grzych, M., Tritz, T., Mason, J., Bravin, M., and Sharpsten, A., (2015), "Studies of Cloud Characteristics Related to Jet Engine Ice Crystal Icing Utilizing Infrared Satellite Imagery," SAE 2015 International Conference on Icing of Aircraft, Engines, and Structures, SAE Technical Paper 2015-01-2086.

[6] Grzych, M.L., "Avoiding Convective Weather Linked to Ice-Crystal Icing Engine Events," AERO. Vol. Qtr. 1, The Boeing Company, Seattle, WA, 2010. p. 23-28.

[7] Nilamdeen, S., Habashi, W. G., Aubé, M. S., and Baruzzi, G. S., (2009), "FENSAP-ICE: Modeling of Water Droplets and Ice Crystals," 1st AIAA Atmospheric and Space Environments Conference, AIAA-2009-4128.

[8] Liao, S., Liu, X., and Feulner, M., (2011), "An Analysis of Turbofan Inlet Water and Ice Concentration Effects in Icing Conditions," SAE 2011 International Conference on Aircraft and Engine Icing and Ground Deicing SAE Technical Paper 2011-38-0050.

[9] Mazzawy, R., (2011), "Critical Point Evaluation of Ice Crystals in Turbofan Engines," SAE Technical Paper 2011-38-0049, SAE 2011 International Conference on Aircraft and Engine Icing and Ground Deicing.

[10] Tsao, J., Struk, P. M., and Oliver, M. J., (2014), "Possible Mechanisms for Turbofan Engine Ice Crystal Icing at High Altitude," 6th AIAA Atmospheric and Space Environments Conference, AIAA-2014-3044.

[11] Bidwell, C., (2011), "Particle Trajectory and Icing Analysis of the E3 Turbofan Engine Using LEWICE3D Version 3," SAE 2011 International Conference on Aircraft and Engine Icing and Ground Deicing SAE Technical Paper 2011-38-0048.

[12] Bidwell, C., (2012), "Ice Particle Transport Analysis with Phase Change for the E3 Turbofan Engine Using LEWICE3D Version 3.2," 4th AIAA Atmospheric and Space Environments Conference, AIAA-2012-3037.
[13] Feulner, M., Liao, S., Rose, B., and Liu, X., (2015), "Ice Crystal Ingestion in a Turbofan Engine," SAE 2015 International Conference on Icing of Aircraft, Engines, and Structures, SAE Technical Paper 2015-01-2146.

[14] Grift, E., Norde, E., Van der Weide, E., and Hoeijmakers, H., (2015), "Computational Method for Ice Crystal Trajectories in a Turbofan Compressor," SAE 2015 International Conference on Icing of Aircraft, Engines, and Structures, SAE Technical Paper 2015-01-2139.

[15] Rigby, D. L., Veres, J., and Bidwell, C., (2015), "Three Dimensional Simulation of Flow in an Axial Low Pressure Compressor at Engine Icing Operating Points," SAE 2015 International Conference on Icing of Aircraft, Engines, and Structures, SAE Technical Paper 2015-012132.

[16] Soeder, R.H., (1994), "NASA Lewis Propulsion Systems Laboratory Customer Guide Manual," NASA-TM106569, August.

[17] Griffin, T.A., Dicki, D.J., Lizanich, P.J., (2014), "PSL Icing Facility Upgrade Overview," AIAA-2014-2896, $6^{\text {th }}$ AIAA Atmospheric and Space Environments Conference, AIAA Aviation Forum, June, Atlanta, GA.

[18] Grandin, A., Merle, J., Weber, M., Strapp, J. W., Protat, A., and King, P., (2014), "AIRBUS Flight Tests in High Total Water Content Regions," 6th AIAA Atmospheric and Space Environments Conference, AIAA-2014-2753.

[19] Leroy, D., Fontaine, E., Schwarzenboeck, A., Strapp, J. W., Lilie, L., Delanoe, J., Protat, A., Dezitter, F., and Grandin, A., (2015), "HAIC/HIWC Field Campaign Specific Findings on PSD Microphysics in High IWC Regions from In Situ Measurements: Median Mass Diameters, Particle Size Distribution Characteristics and Ice Crystal Shapes," SAE 2015 International Conference on Icing of Aircraft, Engines, and Structures, SAE Technical Paper 2015-01-2087.

[20] Leroy, D., Coutris, P., Emmanuel, F., Schwarzenboeck, A., Strapp, J. W., Lilie, L. E., Korolev, A., McFarquhar, G., Dezitter, F., and Grandin, A., (2016), "HAIC/HIWC field campaigns - Specific findings on ice crystals characteristics in high ice water content cloud regions," 8th AIAA Atmospheric and Space Environments Conference, AIAA-2016-4056.

[21] Strapp, J. W., Lilie, L. E., Ratvasky, T. P., Davison, C. R., and Dumont, C., (2016), "Isokinetic TWC Evaporator Probe: Development of the IKP2 and Performance Testing for the HAIC-HIWC Darwin 2014 and Cayenne Field Campaigns," 8th AIAA Atmospheric and Space Environments Conference, AIAA-2016-4059.

[22] Wolde, M., Nguyen, C., Korolev, A., and Bastian, M., (2016), "Characterization of the Pilot X-band radar responses to the HIWC environment during the Cayenne HAIC-HIWC 2015 Campaign," 8th AIAA Atmospheric and Space Environments Conference, AIAA-2016-4201.

[23] Jorgenson, P.C.E., Veres, J.P., Wright, W.B., Struk, P.M., (2013), "A Model to Assess the Risk of Ice Accretion Due

This material is declared a work of the U.S. Government and is not subject to copyright protection in the United States. Approved for public release; distribution is unlimited. 
to Ice Crystal Ingestion in a Turbofan Engine and its Effects on Performance," NASA-TM-2013-218094, November.

[24] Oliver, M.J., (2014), "Validation Ice Crystal Icing Engine Test in the Propulsion Systems Laboratory at NASA Glenn Research Center," AIAA-2014-2898, 6th AIAA Atmospheric and Space Environments Conference, AIAA Aviation Forum, June, Atlanta, GA.

[25] Flegel, A.B., Oliver, M.J., (2016), "Preliminary Results from a Heavily Instrumented Engine Ice Crystal Icing Test in a Ground Based Altitude Test Facility," AIAA2016-3894, 8th AIAA Atmospheric and Space Environments Conference, AIAA Aviation Forum, June, Washington, DC.

[26] Chapman, J.W., Lavelle, T.M., May, R.D., Litt, J.S., Guo,T-H., (2014), "Toolbox for the Modeling and Analysis of Thermodynamic Systems (T-MATS) User's Guide," NASA/TM-2014-216638, January.

[27] Veres, J.P., Jorgenson, P.C.E, Jones, S.M., (2014), "Modeling the Deterioration of Engine and Low Pressure Compressor Performance During a Roll Back Event Due to Ice Accretion," AIAA 2014-3842, 50th AIAA/ASME/SAE/ASEE Joint Propulsion Conference Cleveland, OH, July.

[28] Veres, J.P., (2009), “Axial and Centrifugal Compressor Mean Line Flow Analysis Method," AIAA-2009-1641, 47th Aerospace Sciences Meeting, Orlando, Florida, January 5-8.

[29] Jorgenson, P.C.E., Veres, J.P., May, R.D., Wright, W.B., (2011), "Engine Icing Modeling and Simulation (Part I): Ice Crystal Accretion on Compression System Components and Modeling its Effects on Engine Performance," 2011-38-0025, SAE International Conference on Aircraft and Engine Icing and Ground Deicing, Chicago, IL, Jun 13-17. doi:10.4271/2011-380025

[30] Goodwin, R.V., Dischinger, D.G., (2014), “Turbofan Ice Crystal Rollback Investigation and Preparations Leading to Inaugural Ice Crystal Engine Test at NASA PSL-3 test Facility," AIAA-2014-2895, 6th AIAA Atmospheric and Space Environments Conference, AIAA Aviation Forum, June, Atlanta, GA.

[31] Soeder, R.H., (1994), "NASA Lewis Propulsion Systems Laboratory Customer Guide Manual," NASA-TM106569, August 1.

[32] Thomas, Q.P., (2015), "NASA Glenn Propulsion Systems Lab (PSL) Icing Facility Update," SAE 2015 International Conference on Icing of Aircraft, Engines, and Structures, June 22 - 25, Prague, Czech Republic. 